\title{
Conditioning of the rabbit (Oryctolagus cuniculus) nictitating membrane response as a function of trials per session and ISI with a short intersession interval
}

\author{
W. RONALD SALAFIA, ANTHONY P. DASTON, and LINDA J. MARTINO \\ Fairfield University, North Benson Road, Fairfield, Connecticut 06430
}

\begin{abstract}
The nictitating membrane response of the rabbit was conditioned using either 15 or 60 trials per session at interstimulus intervals of either 250 or 1,000 msec. The intertrial interval was 30 sec, and the intersession interval was $2 \mathrm{~h}$ for all groups. Acquisition was superior at the lower number of trials per session for each ISI, but the effects of the trials per session variable were greater at 1,000 -msec ISI. This pattern of results paralleled the pattern found in other studies when animals are conditioned using a 24 -h intersession interval.
\end{abstract}

Several recent investigators of the effects of number of trials per session (NTS) have found that acquisition rate is inversely related to NTS (Hupka, Massaro, \& Moore, 1968; Kehoe \& Gormezano, 1974; Levinthal, 1973; Salafia, Terry, \& Daston, 1975). In one of these (Salatia et al.), interstimulus interval (250- or 1,000 -msec ISI) and intertrial interval (30- or 90 -sec ITI) were manipulated over an extensive range of NTS (5, 15, 30, 60, or $120 \mathrm{TS})$. Acquisition rate, CR-onset latency, and stability of conditioning were found to be systematically related to all three variables, with faster acquisition, shorter latency, and greater stability generally resulting from conditioning at the lower NTS, shorter ISI, and shorter ITI. In addition, differences in conditioning rate attributable to ISI diminished with diminishing NTS. Levinthal (1973) has shown that the ISI function actually reverses between 5 and 1 TS, such that at 1 TS, conditioning is more rapid at a usually "nonoptimal" ISI.

The present experiment was designed to evaluate whether the same relationships would hold through a reduction of intersession interval from the usual $24 \mathrm{~h}$ to $2 \mathrm{~h}$. The $2-\mathrm{h}$ interval was chosen because it is short compared to the usual 24-h interval and because it permitted groups to be run at relatively disparate NTS while maintaining relatively small differences in the time between the end of one session and the beginning of the next.

\section{METHOD}

\section{Subjects}

Subjects were 27 naive male and female New Zealand rabbits, 70 to 100 days old at the start of the experiment. They were maintained

This research was supported in part by NSF Grant 003274 . Portions of the study were read at the annual meeting of the Psychonomic Society, St. Louis, 1972. Requests for reprints should be sent to W. Ronald Salafia. Department of Psychology, Fairfield University, Fairfield, Connecticut 06430. on ad-lib food and water and housed in light- and climate-controlled quarters.

\section{Apparatus}

Four rabbits were run concurrently in separate sound-attenuated cubicles, serviced independently by control and recording equipment located in an adjoining room. A panel in front of each subject contained two impedance matched speakers used to present the auditory conditioned stimulus (CS) and a continuous white noise for masking during the ITI. A four-channel shock source delivered the US to two stainless steel wound-clip electrodes attached circumorbitally.

Immediately prior to each experimental session, animals were placed in Plexiglas restraining boxes. Movements of the nictitating membrane were monitored by a small photoelectric transducer mounted on each subject's head by means of a muzzle-like assembly and mechanically coupled to a surgical-silk suture in the membrane. Signals from the transducers were interfaced through a four-channel control unit, then amplified and graphically recorded by a Beckman R411 polygraph, a CR being defined as a pen deflection of at least $1 \mathrm{~mm}$ occurring within the ISI. Similar apparatus and procedures have been described and illustrated in detail by Gormezano (1966).

\section{Procedure}

Twenty-four hours prior to the first experimental session, subjects were prepared by having a surgical silk loop inserted into the nictitating membrane of the right eye, under local anesthetic (.5\% Proparocaine Hydrochloride), and wound-clip electrodes attached circumorbitally, approximately $5 \mathrm{~mm}$ below the inferior eyelid and $5 \mathrm{~mm}$ posterior to the temporal canthus. Next, each subject was placed in one of four cubicles for a $15-\mathrm{min}$ period of adaptation to the cubicle and the 66-dB SPL masking noise.

Conditioning sessions were begun on the following day. Animals were randomly assigned to one of four experimental conditions in a 2 by 2 design with either 250 - or 1,000 -msec ISI, and either 15 or 60 TS. The intersession interval from the beginning of one session to the beginning of the next was $2 \mathrm{~h}$ for all groups, although the time elapsing from the end of one session to the beginning of the next varied as a function of session duration, from $90 \mathrm{~min}$ for the $60 \mathrm{TS}$ groups to $112.5 \mathrm{~min}$ for the $15 \mathrm{TS}$ groups. The CS was a continuous $1.000-\mathrm{Hz}$ tone at $85-\mathrm{dB}$ SPL, presented for either 300 or $1.050 \mathrm{msec}$, depending on the ISI. The US was a $3-\mathrm{mA} 60-\mathrm{Hz}$ shock delivered to the wound-clip electrodes and overlapping the last $50 \mathrm{msec}$ of CS presentation. Subjects were run until a criterion of $90 \%$ CRs occurred in any block of 20 consecutive trials. Each was removed at the end of its criterion session and replaced with the 


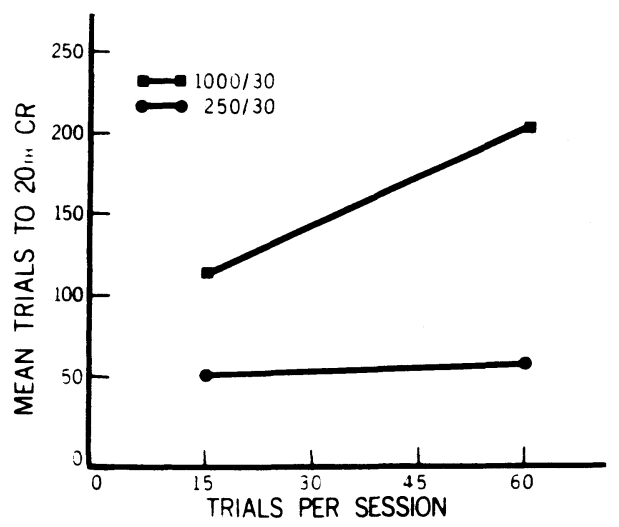

Figure 1. Mean number of trials to the 20th $C R$ as a function of NTS for groups conditioned at the ISI/ITI combinations designated in the legend.

next subject at the beginning of the next session. This assignment procedure resulted in uneven Ns ranging from five to eight subjects per group.

\section{RESULTS}

Figure 1 displays mean number of trials to the 20th $\mathrm{CR}$ for the four groups. More rapid acquisition occurred as a function of the shorter ISI and lesser NTS, with the largest NTS-related difference occurring at the 1,000 -msec ISI. A 2 by 2 factorial analysis of variance (corrected for uneven Ns) computed on the CR criterion data confirmed that there were significant differences as a function of ISI, $F(1.23)=37.14, p<.001$, and NTS, $F(1.23)=$ 6.42, $\mathrm{p}<.025$. as well as a significant ISI by NTS interaction. $\mathrm{F}(1.23)=4.44, \mathrm{p}<.05$.

\section{DISCUSSION}

At both ISIs employed in the present study, acquisition rate was found to be inversely related to NTS. Further, larger NTS-related differences in performance occurred at the longer $(1,000-\mathrm{msec})$ ISI. These results are in complete accord with those of Salafia et al. (1975) using a 24-h intersession interval, so that it may be concluded that the basic NTS and ISI relationships are sufficiently robust to hold through a reduction of the intersession interval from $24 \mathrm{~h}$ to $2 \mathrm{~h}$.

Although the general pattern of results was the same, there were, nevertheless, some differences in the size of effects noted in the two studies. Specifically, while the 250 -msec ISI groups performed at about the same level regardless of intersession interval, the $1.000-\mathrm{msec}$ ISI groups of the Salafia et al. study ( $24 \mathrm{~h}$ interval) conditioned more rapidly than the corresponding groups in the present study (2-h interval). Clearly, such comparisons of specific data points from different experiments should be made cautiously (if at all). Nevertheless, these results do suggest that the processes underlying memory require larger amounts of time to be complete at longer ISIs than at shorter ones.

\section{REFERENCES}

Gormezano, I. Classical conditioning. In J. B. Sidowski (Ed.), Experimental methods and instrumentation in psychology. New York: McGraw-Hill, 1966.

Hupka, R. B., Massaro, D. W., \& Moore, J. W. Yoked comparisons of instrumental-avoidance and classical conditioning of the rabbit nictitating membrane response as a function of interstimulus interval and number of trials per day. Psychonomic Science, 1968, 12, 93-94.

Kehoe. E. J., \& Gormezano, I. Effects of trials per session on conditioning of the rabbit's nictitating membrane response. Bulletin of the Psychonomic Society, 1974, 4, 434-436.

LeVinthal, C. F. The CS-US interval function in rabbit nictitating membrane response conditioning: Single vs. multiple trials per conditioning session. Learning and Motivation, 1973, 4, 259-267.

Salafia, W. R., Terry, W. S., \& Daston, A. P. Conditioning of the rabbit (Oryctolagus cuniculus) nictitating membrane response as a function of trials per session, ISI, and ITI. Bulletin of the Psychonomic Society, 1975, 6, 505-508. 